\title{
Residency Training: Enhancing resiliency in our residents
}

\section{Combining the principles of business and neurobiology}

Rafael H. Llinas, MD, Elisabeth B. Marsh, MD, and Charlene E. Gamaldo, MD

Neurology ${ }^{\circledR}$ 2018;91:e1721-e1723. doi:10.1212/WNL.0000000000006431
Correspondence

Dr. Llinas

rllinas@jhmi.edu

Burnout is a syndrome defined by 3 principal components: emotional exhaustion, depersonalization, and diminished feelings of personal accomplishment. ${ }^{1}$ Burnout negatively affects patient care, affects patient safety, and results in deleterious effects on practitioners. ${ }^{2}$ A recently published article reports that $73 \%$ of neurology residents describe at least one symptom of burnout. ${ }^{3}$

\section{Burnout: The business perspective}

As we consider the alarming rate of burnout in our profession, consider the New York Times opinion piece "Why You Hate Work":

\begin{abstract}
Demand for our time is increasingly exceeding our capacity — draining us of the energy we need to bring our skill and talent fully to life. Increased competitiveness and a leaner, post-recession workforce add to the pressures. The rise of digital technology is perhaps the biggest influence, exposing us to an unprecedented flood of information and requests that we feel compelled to read and respond to at all hours of the day and night. ${ }^{4}$
\end{abstract}

As we begin to contemplate strategies to mitigate burnout, it might be useful to take a page from the business literature regarding employee satisfaction:

\begin{abstract}
"Employees are vastly more satisfied and productive, it turns out, when four of their core needs are met:
Physical: maximal opportunities to renew and recharge at work

Emotional: feeling valued and appreciated for their contribution

Mental: maximal opportunity to maximally focus on their most important tasks with autonomy to define when and where they get their work done

Spiritual: maximal opportunity to do what you do best and enjoy most of the time to maintain a sense of higher purpose and connection to your work."
\end{abstract}

\section{Burnout: The neuroscientist perspective}

We should first consider the etiology of burnout from a neurophysiologic standpoint: where does it localize? The most likely location is prefrontal cortex. The prefrontal lobe functions to (1) adjust and adapt social behaviors within one's immediate environment, (2) plan and execute complex motor and cognitive behaviors, and (3) carry out and perform critical decisions. ${ }^{5}$ The prefrontal lobe applies the experiential information from the past to the contextual information in the present and make decisions on how best to interact and navigate in one's immediate environment. Proper prefrontal functioning is essential for professional conduct. However, an environment of increasing stressors and fewer victories accelerates the rate of prefrontal fatigue. This is compounded by the exquisite vulnerability of the prefrontal lobe to sleep loss; the effect of sleep deprivation (less than 7 hours a night) is notable in as little as 7 days. It is no wonder that many individuals fall victim to unprofessional behavior and burnout. 
To combat burnout, one must consider the concept of resiliency. Resiliency is the ability to maintain optimism, adaptability, initiative, tolerance, organizational skills, teamwork, professionalism, assertiveness, humor, and a sense of self-worth, even in times of stress. ${ }^{6}$ The term is often confused with "grit," arguably more "trait-like," as it defines an individual's level of courage, resolve, and the strength of character. As neurologists, we are in a unique position to understand resiliency from the perspective of our executive function with variable expression based on state and context. Resiliency should be seen more as a dynamic state that can be enhanced and recharged through proper self-care, awareness, and a supportive environment (figure). At our institution, we have implemented several initiatives to promote resiliency focused on physical, emotional, mental, and spiritual renewal.

\section{Enhancing resilience}

\section{Physical renewal}

Physical renewal requires regular exercise and consistent sleep habits. One way this can be accomplished is by inserting a sense of community. At our institution, residents may join the hospital gym for free. In addition, some neurology residents (and faculty) participate in the Ragnar team run, a 200mile relay that relies on teamwork and cooperation. We have also adopted initiatives to encourage activity and bonding including Resident Appreciation Day and Resident Retreats, where residents spend the afternoon together taking part in a fun activity such as Thai cooking or paintball.

\section{Emotional renewal}

Emotional renewal requires increasing the number of victories and tilting the balance towards meaningful tasks directly aimed at professional development and fulfillment. To optimize success, we should reconsider the current focus on removing "scut" (defined by many to include drawing blood, placing nasogastric tubes, putting in central lines, and performing lumbar punctures) since conducting these tasks, especially when successfully performed, can serve as an instant sense of accomplishment. We should instead focus on eliminating more of the secretarial tasks that do not require specific medical training for completion. Meaningful tasks may vary depending on level of training. As an example, we have found that medical students enjoy and learn more on their outpatient rotation if they are given more direct patient care-related responsibilities such as electronic medical records (EMR) documentation, taking histories, and presenting patients. ${ }^{7}$ This may seem antithetical, as one might expect greater job satisfaction when the job demands less, but these examples suggest that the demands that most closely correspond to your purpose (immediate patient care and wellness) is a critical component in achieving emotional renewal. While residents also value direct patient care, EMR documentation likely does not result in the same emotional reward, while leading a difficult family meeting or completing a complicated procedure is incredibly fulfilling.

\section{Mental renewal}

Mental renewal requires improved focus. In a recent article, neurosurgeons reported lower rate of burnout than neurologists. $^{2}$ The operating room is a sanctuary from the distraction of calls, pages, texts, and emails. It represents a protected place in time and space to hone their craft and calling. Unlike the neurology resident who may feel bombarded by the aforementioned distractions, these same external demands remain outside of the surgery suite so that the neurosurgical resident in training has the protected time to fully absorb the victory of the complex surgical case. The opportunity to focus on a single task to completion without interruption is a human intellectual need that is most under assault by our pagers and text messages. As neurologists, we must consider reevaluating the concept of elective time to utilize it properly and productively in a similar manner. Elective time is not a vacation and perhaps should be more appropriately named selective time- - a time to do medicine in an uninterrupted fashion, to read, reflect, and rediscover the intellectual aspect of our chosen field.

\section{Spiritual renewal}

Spiritual renewal requires recognition of a higher purpose. Medicine remains a revered and respected profession in our society; however, stricter work hour limitations and increased regulatory burden has increased the level of stress and focus on the act of solely completing tasks. At our institution, to help residents feel anchored with a sense of purpose, we encourage frequent and formal meetings with mentors that include discussion of both short and long-term career goals. This is based on evidence that the exercise of articulating one's goals helps to solidify purpose and increases the likelihood of

Figure Conceptual framework for the drained resident and solutions towards recharge and resiliency
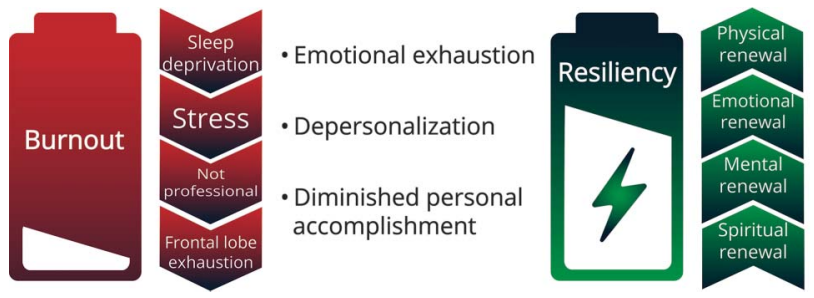

- Renew and recharge

- Feel valued and appreciated

- Autonomy

- Maintain sense of

higher purpose 
achieving them. ${ }^{8}$ Confirmation of purpose is reinforced by recognition. To recognize resident efforts, we present annual awards for citizenship (the Fogelson Award for Humanity in Medicine to residents performing outstanding patient care). In addition, every year, our PGY $2 s$ and $3 s$ are met with a surprise day off, and each class is encouraged to do an activity together, promoting class cohesion. Finally, residents are reminded of their value and contribution by serving as mentors and teachers and we encourage our residents to participate in mentoring and educational outlets within and outside the institution.

\section{Putting it all together}

In our residency program, the PGY 4s spend their clinical time as the chief resident, single-handedly running the clinical service. It is an almost universally loved rotation. It is difficult, the hours are long, and the case load can be heavy. However, the focus is on directing care. There are no notes, no bills, no talking to insurance companies, no negotiating with colleagues. In this role, the chief (with backup support as needed by their faculty attending) assumes the role of leading the team of junior residents to ensure the care of the patient is the highest quality. They enjoy the job because they are responsible. They feel empowered, and they do almost nothing that is not for the benefit of the patient or the education of their team. Jennings and Slavin ${ }^{9}$ cite the "balance between effort and reward" as one of the 6 variables contributing to work stress that propagates burnout. In the past, we were able to better appreciate the balance between effort and reward because we had less onerous administrative regulations and oversight, freeing us to assume a more appreciable sense of contribution to our patients' care. Our PGY4s get the chance to process and reflect on their victories each day. Resetting the balance between effort and reward while providing opportunities to process victories are now active parts of our educational goal for neurology trainees at all levels of training.

\section{Acknowledgment}

Paula David edited the manuscript for nonintellectual content. Bryan Sexton's work at Duke on this subject and course on resiliency shaped many of the concepts in this article. The authors thank Seulah Choi for her artistic contribution for the figure.

\section{Study funding}

No targeted funding reported.

\section{Disclosure}

The authors report no disclosures relevant to the manuscript. Go to Neurology.org/N for full disclosures.

\section{References}

1. Maslach C, Schaufeli WB, Leiter MP. Job burnout. Annu Rev Psychol 2001;52: 397-422.

2. Busis NB, Shanafelt TD, Keran CM, et al. Burnout, career satisfaction, and well-being among US neurologists in 2016. Neurology 2017;88:797-808.

3. Levin KH, Shanafelt TD, Keran CM, et al. Burnout, career satisfaction, and well-being among US neurology residents and fellows in 2016. Neurology 2017;89:492-501.

4. Schwartz T. Why You Hate Work. New York: New York Times; May-June 2014: SR1.

5. Yang Y, Raine A. Prefrontal structural and functional brain imaging findings in antisocial, violent, and psychopathic individuals: a meta-analysis. Psychiatry Res 2009; 174:81-88.

6. Matheson C, Robertson HD, Elliot AM, Iversen L, Murchie P. Resilience of primary healthcare professionals working in challenging environments: a focus group study. BR J Gen Pract 2016;66:e507-e515.

7. Tanner JA, Rao KT, Salas RES, et al. Incorporating students into clinic may be associated with both improved clinical productivity and educational value Neurology. Clin Pract 2017;7:474-482.

8. Strowd RE, Salas REM, Cruz TE, Gamaldo CE. Neurology clerkship goals and their effect on learning and satisfaction. Neurology 2016;86:684-691.

9. Jennings ML, Slavin SJ. Resident wellness matters: optimizing resident education and wellness through the learning environment. Acad Med 2015;90:1246-1250. 


\section{Neurology}

\section{Residency Training: Enhancing resiliency in our residents: Combining the principles of business and neurobiology}

Rafael H. Llinas, Elisabeth B. Marsh and Charlene E. Gamaldo

Neurology 2018;91;e1721-e1723

DOI 10.1212/WNL.0000000000006431

This information is current as of October 29, 2018

Updated Information \&
Services
References
Citations
Subspecialty Collections
Permissions \& Licensing
Reprints

\section{Updated Information \&}

References

\section{Citations}

\section{Subspecialty Collections}

Reprints including high resolution figures, can be found at: http://n.neurology.org/content/91/18/e1721.full

This article cites 8 articles, 4 of which you can access for free at: http://n.neurology.org/content/91/18/e1721.full\#ref-list-1

This article has been cited by 2 HighWire-hosted articles: http://n.neurology.org/content/91/18/e1721.full\#\#otherarticles

This article, along with others on similar topics, appears in the following collection(s):

All Clinical Neurology

http://n.neurology.org/cgi/collection/all_clinical_neurology

Information about reproducing this article in parts (figures,tables) or in its entirety can be found online at:

http://www.neurology.org/about/about_the_journal\#permissions

Information about ordering reprints can be found online:

http://n.neurology.org/subscribers/advertise

Neurology ${ }^{\circledR}$ is the official journal of the American Academy of Neurology. Published continuously since 1951, it is now a weekly with 48 issues per year. Copyright () 2018 American Academy of Neurology. All rights reserved. Print ISSN: 0028-3878. Online ISSN: 1526-632X.

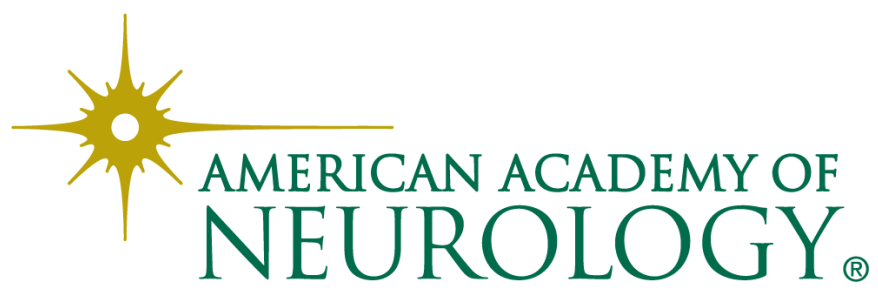

